CLAWAR 2018: 21st International Conference on Climbing and Walking Robots and the Support Technologies for Mobile Machines, Panama City, Panama, 10-12 September 2018

\title{
KINETIC ANALYSIS OF AN ANKLE REHABILITATOR COMPOSED OF TWO PARALLEL DELTA ROBOTS
}

\author{
MIGUEL PÉREZ BAYAS \\ Escuela Superior Politécnica de Chimborazo \\ perezmiguel3877@gmail.com \\ Riobamba-Ecuador \\ GEOVANNY NOVILLO ANDRADE \\ Escuela Superior Politécnica de Chimborazo \\ gnovillo@espoch.edu.ec \\ Riobamba-Ecuador \\ SÓCRATES MIGUEL AQUINO ARROBA \\ Escuela Superior Politécnica de Chimborazo \\ saquino@espoch.edu.ec \\ Riobamba-Ecuador \\ JAVIER GAVILANES CARRIÓN \\ Escuela Superior Politécnica de Chimborazo \\ javier.gavilanes@espoch.edu.ec \\ Riobamba - Ecuador
}

The present research shows the kinetic analysis of an ankle rehabilitator, the rehabilitation mechanism consists of a fixed platform in which there are two inverted delta robots linked a mobile platform, actuator are controlled by servomotors which provide six basic movements of ankle rehabilitation like dorsiflexion, plantar flexion, inversion, eversion, abduction and adduction, which was verified through a motion study and singularity analysis. The design of the rehabilitator is based on the establishment of a methodology that allows the development of a machine that achieves all the ergonomic, technological and quality requirements, using tools of computational mechanics that allowed generating a virtual model able to generate the required movements and supporting the mechanical stress generated. The mechanism was modeled in CAD software such as SolidWorks, with the virtual model is possible to analyze the inverse and direct kinematics determining the position and speed of the joints, for the selection of the servomotors the dynamic analysis was made, obtaining the accelerations, forces and torques using the MSC Adams software. For the analysis of deformations, normal stresses and shear forces, the CAE software such as ANSYS was used, which works on the basis of the finite element method, with its Workbench platform and its structural analysis module. Finally, the machine was built using $3 \mathrm{D}$ printing and performance tests were carried out. 


\section{Robotic rehabilitation}

\subsection{Introduction}

The Lower limbs injuries and the ankle injuries are very frequent so they require highly qualified professionals for the rehabilitation process, making it necessary to develop machines that help the rehabilitation processes quickly and without risk to cause harm to the patient.

By designing a system of inverted delta robots we can solve problems such as: efficiency in ankle rehabilitation, prolonged ankle rehabilitation without fatigue of the rehabilitator, suppling the demand of people that need of rehabilitation of the ankle and giving solution to athletes who usually suffer the ankle injuries and they need rehabilitation therapies.

In the rehabilitation of the ankle, unique movements are generated, these movements describe the rehabilitation process of the ankle with mobility ranges, and these movements are described below:

Dorsiflexion, plantar flexion, inversion, eversion, abduction / external rotation, adduction / internal rotation, these rehabilitation movements are shown in Figure 1 [13].

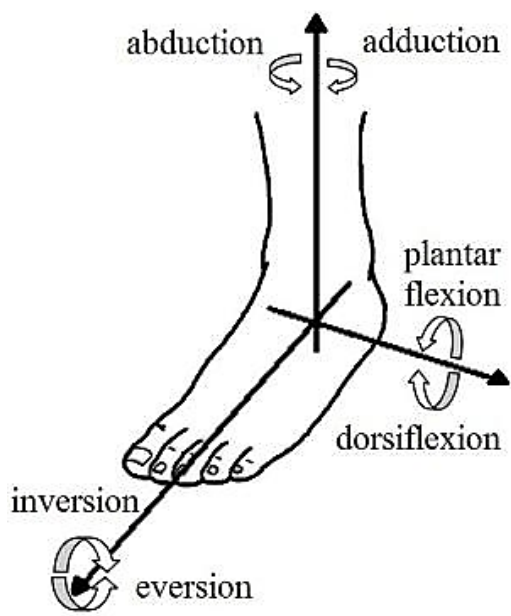

Figure 1. Ankle movements for rehabilitation process.

Figure 1 shows the movements of ankle rehabilitation, these movements have permissible ranges, Table 1 shows the movements with the necessary ranges for a correct rehabilitation process without causing harm to the patient, and the design of the robot for rehabilitation is based on the permissible ranges shown in Table1. 
Table 1. Range of movements for ankle rehabilitation

\begin{tabular}{cc}
\hline KIND OF MOVEMENT & $\begin{array}{c}\text { MAXIMUM } \\
\text { ALLOWABLE } \\
\text { MOVEMENT }\end{array}$ \\
\hline Dorsiflexion & $20,3^{\circ}-29,8^{\circ}$ \\
\hline Plantar flexion & $37,6^{\circ}-45,8^{\circ}$ \\
\hline Inversion & $14,5^{\circ}-22,0^{\circ}$ \\
\hline Eversion & $10,0^{\circ}-17,0^{\circ}$ \\
\hline Abduction/external rotation & $15,4^{\circ}-25,9^{\circ}$ \\
\hline Adduction/internal rotation & $22,0^{\circ}-36,0^{\circ}$ \\
\hline
\end{tabular}

A parallel robot is composed of a final effector with $n$ degrees of freedom and a fixed base, joined together by at least two independent kinematic chains. The robot is driven by $\mathrm{n}$ simple actuators [9]. Currently the development and applications of delta robots has been very different, due to its speed and precision being widely used in selection processes, 3D printers, etc.

\subsection{Design}

The design methodology includes the design procedures to get the proposed objective [5], [6], [11] and [12]. Figure 3 shows the following stages to get a robotic rehabilitator prototype: preliminary studies, conceptual design, specification design and materialization design. 


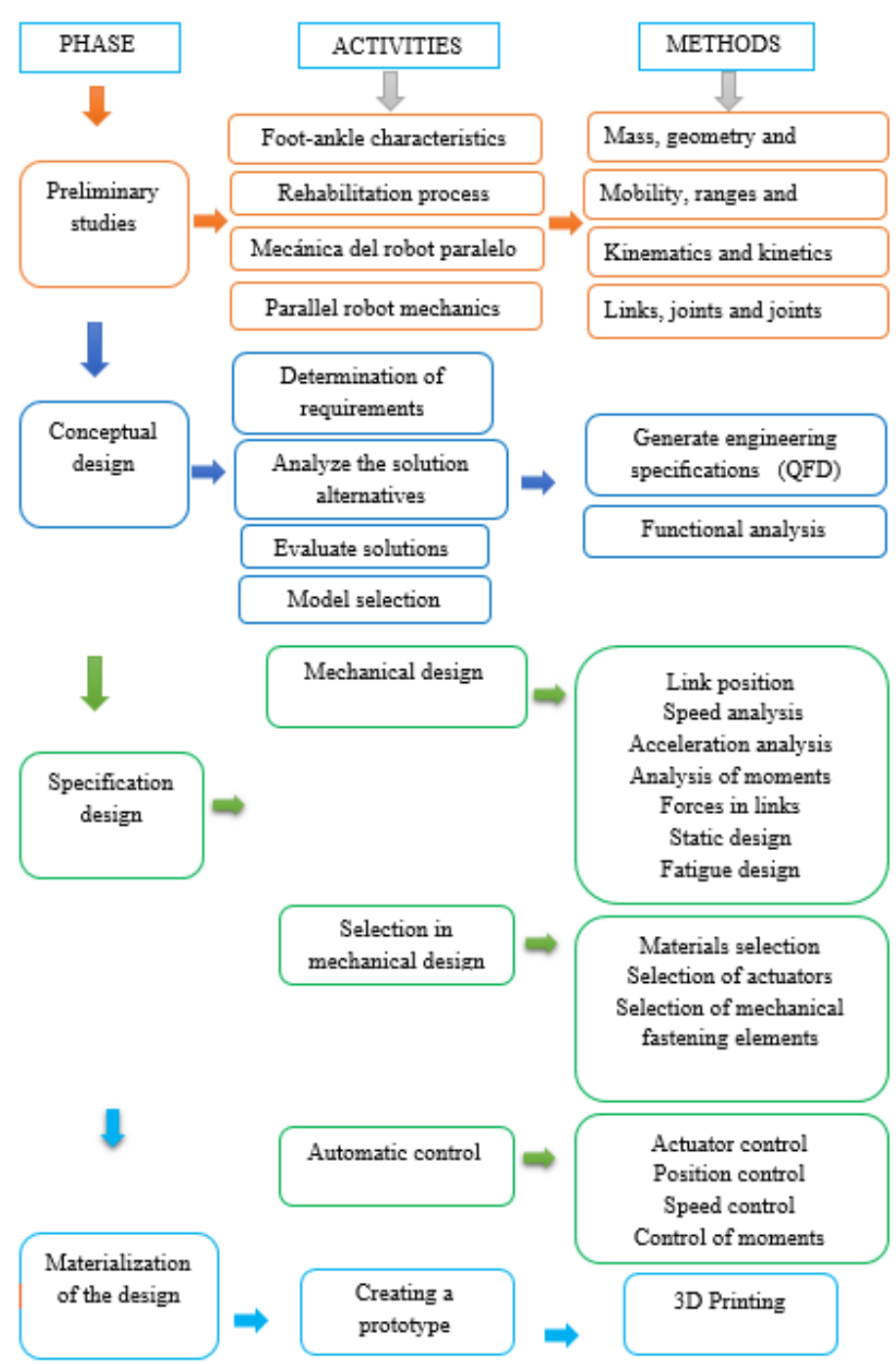

Figure 3. Proposed methodology.

Based in data from Table 1 the prototype allow to reach the movement for ankle rehabilitation.

- The dorsiflexion movement reaches $25^{\circ}$ of inclination of the platform.

- The plantar flexion movement reaches 45.8 of inclination of the platform.

- The investment movement reaches $19.5^{\circ}$ of inclination of the platform.

- The eversion movement reaches $15^{\circ}$ inclination of the platform.

- The abduction movement reaches $22^{\circ}$ of inclination of the platform. 
- The adduction movement reaches $30.06^{\circ}$ of inclination of the platform, Figure 4 shows this position.

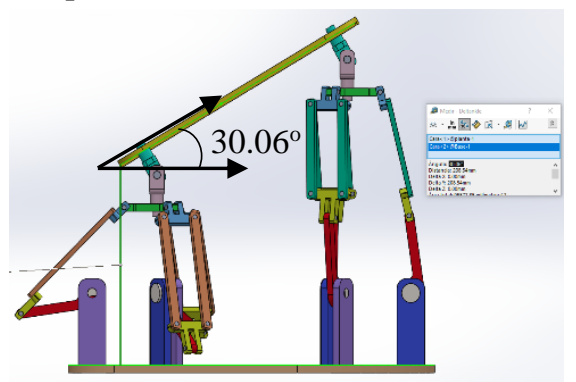

Figure 4. Maximum angle reached in plantar adduction movement by the robot

\section{Cinematic Analysis}

The resolution of the direct kinematic problem allows knowing which is the position (x, y, and $\mathrm{z}$ ) and orientation $(\theta, \varnothing$ and $\varphi)$ adopted by the effector of the robot when each of the variables that limit the orientation of its joints takes determined values, so that to solve a direct kinematic problem it will be given by the relations of position and speed:

$$
\begin{aligned}
& x=f_{x}\left(q_{1}, q_{2}, q_{3}, q_{4}, q_{5}, q_{6}\right) \\
& y=f_{y}\left(q_{1}, q_{2}, q_{3}, q_{4}, q_{5}, q_{6}\right) \\
& z=f_{z}\left(q_{1}, q_{2}, q_{3}, q_{4}, q_{5}, q_{6}\right) \\
& \varnothing=f_{\alpha}\left(q_{1}, q_{2}, q_{3}, q_{4}, q_{5}, q_{6}\right) \\
& \theta=f_{\beta}\left(q_{1}, q_{2}, q_{3}, q_{4}, q_{5}, q_{6}\right) \\
& \varphi=f_{\gamma}\left(q_{1}, q_{2}, q_{3}, q_{4}, q_{5}, q_{6}\right) \\
& x=\sum_{1}^{n} \frac{\partial f_{x}}{\partial q_{i}} \dot{q}_{i} \\
& \dot{y}=\sum_{1}^{n} \frac{\partial f_{y}}{\partial q_{i}} \dot{q}_{i} \\
& \dot{z}=\sum_{1}^{n} \frac{\partial f_{z}}{\partial q_{i}} \dot{q}_{i} \\
& \dot{\emptyset}=\sum_{1}^{n} \frac{\partial f_{\emptyset}}{\partial q_{i}} \dot{q}_{i} \\
& \dot{\theta}=\sum_{1}^{n} \frac{\partial f_{\theta}}{\partial q_{i}} \dot{q}_{i} \\
& \dot{\varphi}=\sum_{1}^{n} \frac{\partial f_{\varphi}}{\partial q_{i}} \dot{q}_{i}
\end{aligned}
$$

Based on the equations shown, Figure 5 shows the complete kinematic analysis of all the actuators based on the position of the final effector generated by MSC Adams. 


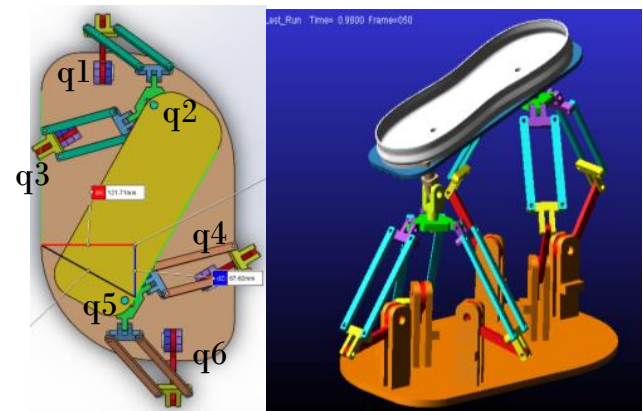

Figure 5. Kinematic analysis based on the position of the final effector generated by MSC Adams.

The kinematic analysis of the delta parallel robot allows demonstrating all the ranges of movement required in the ankle rehabilitation, besides the speeds and accelerations are within the permissible range provided by specialists in ankle rehabilitation.

\section{Dynamic Analysis}

The dynamic studies the forces that act on an object and the movement generated in it. (Barrientos, 2007). For the calculation of the dynamic model of a system of articulated links, the Lagrangian formulation established by the equations shown below will be used.

$$
\begin{aligned}
L & =E_{c}-E_{p} \\
\tau_{i} & =\frac{d}{d t} \frac{\partial L}{\partial \dot{q}_{i}}-\frac{\partial L}{\partial \dot{q}_{i}}
\end{aligned}
$$

Where:

$L$ is the Lagrangian function

$E_{c}$ is the kinetic energy

$E_{p}$ is the potential energy

$q_{i}$ corresponds to the coordinates of the joints

$\tau_{i}$ is the torque applied to the degree of freedom $q_{i}$

The dynamic simulation of the robot allows knowing what type of actuator is required to achieve the movements in the rehabilitation process. In the simulation, a static load of $100 \mathrm{~N}$ is considered as a reference value. Figure 6 shows the Torque-Speed curves of the different actuators of the robot, the curves allow to select the motors for the control. 

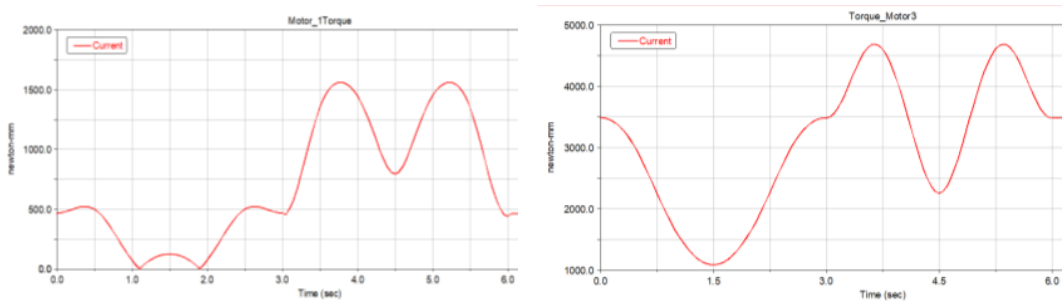

Figure 6. Dynamic analysis generated by MSC Adams.

\section{Mechanical strength analysis}

Finite element method (MEF) is a numerical method for the approach of solutions of complicated partial differential equations used in various engineering problems. Figure 7 shows the deformation due to the load of $100 \mathrm{~N}$, the simulation was generated in the ANSYS software where the deformation ranges can be verified due to the load.

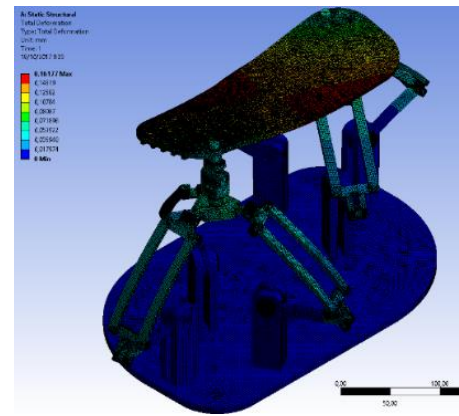

Figure 7. Deformation of the robot due to the static load of $100 \mathrm{~N}$.

\section{Results}

\section{Results of kinematic analysis:}

- The results obtained from the kinematic analysis are as follows: The maximum angular velocity of the actuator_1 is $63.15 \mathrm{deg}$. / s, the maximum angular velocity of the actuator_2 is $58.58 \mathrm{deg}$. / s, the maximum angular velocity of the actuator_3 is $53.46 \mathrm{deg}$. / s, depending on the position of the effector_1 which is $407.342 \mathrm{~mm}$.

- The maximum speed of the actuator_4 is $34.0488 \mathrm{~mm}$. / s, the maximum speed of the actuator_6 is $23.7753 \mathrm{~mm}$. / s depending on the position of the effector_2 which is $174.029 \mathrm{~mm}$. the maximum speed of the actuator_5 is 
$24.5336 \mathrm{deg}$. / s, depending on the position of the effector_2 which is $181.4925 \mathrm{~mm}$.

\section{Dynamic analysis results:}

- The results of the dynamic analysis are described below: The maximum torque reached by motor_01 is $1559.7509 \mathrm{~N} \mathrm{~mm}$. The maximum torque reached by the motor_02 is $2633.2061 \mathrm{~N} \mathrm{~mm}$. The maximum torque reached by the motor_03 is $4689.27 \mathrm{~N} \mathrm{~mm}$ the maximum torque reached by the motor_04 is $3595.1272 \mathrm{~N} \mathrm{~mm}$. The maximum torque reached by the motor_05 is $2594.1011 \mathrm{~N} \mathrm{~mm}$. These values are given as a function of time, the maximum value being that of motor_03, this value helps us to select the actuators for the robot.

\section{Results of resistance analysis:}

- The analysis of mechanical resistance of the delta robot, where the maximum deformation is $0.16177 \mathrm{~mm}$ with a load of $100 \mathrm{~N}$ and the composition of Aluminum with density $=2770 \mathrm{~kg} / \mathrm{m} 3$ shows that the structure will work properly without suffering damage and the equivalent effort von Mises: 21,912Mpa MAX - 1,2083 x 10-8Mpa MIN.

\section{Tests on the prototype}

- The tests in the prototype show that the generated simulations were adequate for the design, obtaining that the prototype generates the necessary movements for the rehabilitation of the ankle.
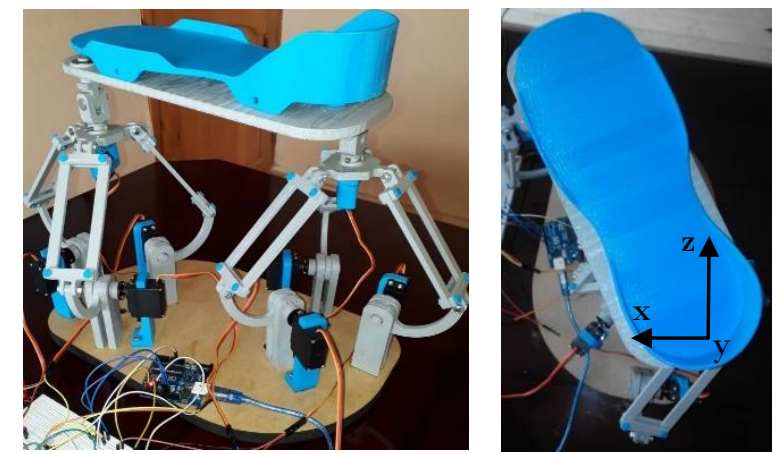

Figure 8. Prototype of ankle rehabilitator generated by $3 \mathrm{~d}$ impression. 


\section{References}

1. Aracil, Rafael, Y Otros. 2006. Robots paralelos: Máquinas con un pasado para una robótica del futuro. págs. 16-28.

2. Barrientos A., Peñin F. L., Balaguer C., Aracil R., (2007) "Fundamentos De Robótica” España editorial McGraw.Hill. Segunda edición.

3. Benjamin, C. 2015. Esguince de tobillo. [En línea]. http://arh.adam.com/content.aspx?productId=102\&pid=7\&gid=100209.

4. Beer P. Ferdinand \& JOHNSTON E. Russell, (2013) "Mecánica de Materiales" editorial McGraw. Hill. Sexta edición.

5. Budynas Richard G., \& Nisbett J. Keith, (2008) "Diseño en ingeniería mecánica de Shigley” editorial McGraw. Hill. Octava edicion.

6. Hamrock J. Bernard, Jacobson B.O, Schmid Steven, (2000) "Diseño de elementos de máquinas" editorial McGraw. Hill.

7. Kumar Saha S., (2010) "Introducción a la robótica” México editorial McGraw.Hill. Segunda edición.

8. Kelly R., Santibáñez V., (2003) "Control de Movimiento de Robots Manipuladores" España Editorial PEARSON educación, S.A. Primera edición.

9. Merlet, J P. 2006. Parallel Robots. Second. Dordrecht: Springer.

10. Moore, Keith L, Dalley, Arthur F Y Agur, Anne M. 2010. Anatomía con orientación clínica. Sexta. Barcelona: Wolters Kluwer.

11. Norton L. Robert, (2009) "Diseño de maquinaria” Editorial McGraw. Hill. Cuarta edición.

12. Peña C; Martínez E; Cárdenas P. (2011) “Optimización dimensional de un robot paralelo tipo delta basado en el menor consumo de energía" Bogota.

13. Saladin, Kennerh. 2013. Anatomía y Fisiología. La Unidad entre Forma y Función. Sexta. México: Mc Graw Hill.

14. Silva, Luis Ángel. 2005. Control visual de robots paralelos. Análisis, desarrollo y aplicación a la plataforma robotenis. Madrid: s.n. 